\title{
The Use of English Prepositions: An Empirical Study
}

\section{J. Saravanan}

\begin{abstract}
This study examined the writing skill of the students at the undergraduate level, with a special focus on the use of prepositions of place, time and direction in English. The subjects of the study comprised of 100 randomly selected undergraduate students of English literature from two Arts and Science colleges located in Coimbatore city. The data elicitation instrument was a guided cloze test in which the subjects were asked to fill the gaps using appropriate prepositions of place, time and direction. To analyze the collected data, socio-linguistic and descriptive methods were used. The results indicated that the students found more difficulties in the use of prepositions of place and direction than the prepositions of time because of their mother tongue interference. The findings imply that teachers should pay more attention while teaching the prepositions of place, time and direction and provide sufficient explanations about them to the students in the classroom.
\end{abstract}

Key words: Preposition, Importance of writing, Socio-linguistics

\section{Introduction}

The English language has attained an international acceptance due to globalization. Most of the learners need to write and speak English fluently and accurately in the general and academic domains. To use English effectively, it is important to master the four language skills, namely listening, speaking, reading and writing (LSRW). Of all the four language skills, writing is considered a complex process and the most important skill for the second language learners to master. The ability to communicate ideas and information effectively through the global network is crucially dependent on good writing skills. However, second language learners are under pressure today in writing because the art of communication has become so complex in conveying their thoughts to a great growing number of English-speaking people. This is often true to those who undertake writing in English as they face difficulties in the use of prepositions particularly, of place, time and direction. The reasons behind this phenomenon are multifarious. One of the reasons for this is due to the student's lack of understanding the context in using appropriate prepositions and they do not know which preposition to use (Cabuk, 2009). The other reason is that 
learners face difficulties in the use of space prepositions due to influence of their native and target languages (Abdulkarim, 2008). Lack of practice is another cause which makes their writing colourless, boring, and ineffective. These difficulties not only affect learners' academic success, but also hinder their professional progress which has a negative impact on their personality and overall growth.

Prepositions are the subtlest and a set of small words that are of a closed class in English language (Huddleston, 1984, p.336). They express a relation between two entities, one being that represented by the prepositional complement, the other by another part of the sentence. The prepositional complement is characteristically a noun phrase, a nominal wh-clause, or a nominal -ing clause. For instance, The book is on the table, Mary is not responsible for what she did, Dylan read the manual before installing the system (Quirk et al. 1985, p.657). Prepositions do not accept new words easily, but they have notoriously polysemous behaviours in sentences. They are difficult to learn as most of them have different functions and they do not have many rules to help in choosing the right prepositions in a particular context (Swan, 2005, p.425). They combine with other parts of speech to express new meanings, and they participate in idiomatic expressions. For instance, Hewas angry at the weather and He was angry with me for failing to keep our appointment. Sometimes, one preposition comes with the verb form, another with the adjective and still another with the noun form of the root word. For instance, sympathize with someone, sympathy for someone and sympathetic to someone (Kennedy, 2003, p. 257).

The basic syntactic properties and semantic functions differ in many languages. In other languages, the prepositions occur after the complement (subject-object-verb).They are called postpositions. In English language, they are usually placed before a noun or a noun equivalent (subject-verb-object). Languages such as English, French, German, and numerous others are prepositional languages whereas Korean, Turkish, Finnish, and lots of others are postpositional languages (Endley, 2010). They often cause problems for second language learners as there are no one-to-one correspondences between English and the other languages. Besides, many prepositions have metaphorical and abstract meanings that a language learner finds difficult to learn. The task of choosing the right preposition is made even more difficult when the preposition is used together with a noun, a verb, or an adjective, especially since there are no general rules by which a preposition is assigned. For instance, She relied on Max, similar to the other one, the author of the book - the prepositions on, to, and of are determined by rely, similar and author respectively. While learning, the various meanings and meaning extensions of prepositions are perhaps the greatest challenge. A pedagogical strategy is essential for students to pay attention to the cooccurrence, collocation, and discourse behaviour of prepositions.

According to Lindstromberg (1998) prepositions are traditionally classified into three categories: prepositions of place, of direction (or motion or movement) and of time. These prepositions pose a challenge to the learners as well as teachers of English because of the uniqueness of the problem involved. The learners face difficulties in the proper usage of prepositions in sentences, and therefore, land in trouble. Besides that, each of these prepositions has various meanings and usages that make the learning process equally difficult. In English, many prepositions are used to describe both spatial and temporal relationships (Clark, 1973; Bennett, 1975; Jackendoff, 1983). Both spatial and temporal 
functions of prepositions may pose challenges on the part of the second language learners (Kemmerer, 2005). Lindstromberg (2010) states that spatial preposition is a physical thing located in relation to another. The meaning of each preposition is spatial to describe these meanings; the trajectory (TR) and the landmark (LM) are defined. For example, The ball is on the table. Here, the preposition on functions as a preposition of place. The phrase, the ball refers to a thing whose location the speaker wants to indicate. It refers to the subject of the preposition. The phrase, the table refers to another thing, the Landmark of the preposition. The preposition locates the Subject (the ball) in relation to the Landmark (the table). The category of spatial prepositions is broadly divided into two groups: prepositions of static location and prepositions of direction (Bennett 1972; Jackendoff 1983; Zwarts 1997; Zwarts \& Winter 2000; Kracht 2002; Zwarts 2005, 2006). When prepositions follow verbs, they become distinct whether they describe the location or direction. For example, the preposition at is used to represent a static location of an object in most cases, e.g. John is waiting for his friend at the store. There are cases in which at represents a direction or a destination, e.g. The dog jumped at my face or we arrived at the park. While the number of spatial prepositions is small, the number and variety of spatial relationships denoted by them are many. This provides an insight into the problems and challenges of the inherent ambiguity and vagueness in the usage and understanding of spatial prepositions (Chung, 2011). (Quirk et al., 1972, p. 377) says that the temporal uses of prepositions frequently suggest metaphorical extensions from the sphere of place. In fact, prepositions of time are very regular and easy to understand as compared to prepositions of place (Hill, 1989, p. 224).

Many prepositions are very versatile, and a lot of research has gone into ways of identifying and organizing the polysemous meanings that a preposition can have. For the most part, however, studies have focused on the meanings of spatial and temporal prepositions (e.g. Boers and Demecheleer, 1998; Brugman 1981, 1984; Cooper 1998; Hawkins 1984; Herskovits 1981, 1986; Jackendoff 1990; Jackendoff \& Landau 1993; Horberg 2006; Lakoff 1987; Langacker 1987; Leech 1969; Lindstromberg 1999; Miller \& JohnsonLaird 1976; Nam 1955; Talmy 1983; Tseng 2000; Tyler \& Evans 2003; Vandeloise 1991).

\section{Review of literature}

Many studies have been done to examine the use of prepositions by second language learners. However, the present study has focused on errors particularly in the use of prepositions of place, of time and of direction. Habash (1982) has investigated the occurrence of students' errors in the use of English prepositions and tested the relationship between the students' achievement in the English language at school and their achievement in the diagnostic test. The researcher found that the errors with spatial prepositions were more frequent than those with temporal prepositions.

Reef (2000) observed the errors in the use of place prepositions and attempted to find out whether such errors were tied to poor teaching or the interference of the first language. The researcher undertook this study to find the level of competence among students in the use of the four types of prepositions namely, position/destination, relative, passage, and orientation. The results revealed that students could not clearly differentiate the four types of the prepositions and they faced difficulties in using the prepositions of position/ destination than the other types. The inability of the students to distinguish the semantic content of these prepositions and poor teaching methods employed by 
teachers are the major reasons for the errors.

Kim (2001) examined the errors in the use of English prepositions in the written work of Upper Secondary Malay students. The aim of the study was to identify the prepositional errors and to find out the causes for the occurrence of these errors. The researcher applied nine concepts of prepositions which pose the most of the difficulties for students namely, prepositions of place, time, direction, manner-agent, cause-purpose, similarity, association, verb-preposition, and adjective-preposition. A diagnostic test was administered to these students to elicit the data. In the test, they were required to write an essay and fill the blanks of a Cloze text and sentences with the correct prepositions. The result of the study showed that the students made a number of errors in using the prepositions of place, time and direction due to wrong selections. The researcher suggested that the method of teaching English prepositions could play a vital role in facilitating the learning of prepositions.

Rumiyati (2008) maintains that the Indonesian learners of English often find difficulties and make errors in the use of English prepositions. The main purpose of her study was to identify and classify the preposition error types. The results showed that preposition of place, time, manner, direction, purpose, measurement, similarity, capacity and association were considered difficult for the students and mastery of using prepositions were still poor. It further showed that students find remarkably more difficulties in the use of prepositions of direction (91.35\%) than the other types. The researcher suggested that prepositions need more attention on teaching and learning English.
Ahmad (2011) attempted the learning problems and analysed the errors in the use of articles and prepositions. The instrument used in the study was the essays written by $8^{\text {th }}$ class students in their annual examination. The findings of the study showed that the secondary school students faced difficulties in learning prepositions of time and were confused while using prepositions in their writings.

The studies on prepositions mentioned above showed that many studies have been done on prepositions from different perspectives. However, in the case of second language learners of English, particularly undergraduate students in Coimbatore district, Tamil Nadu, India, no research has been carried out on the topic of prepositions of place, time and direction. It is the hope that the present study provides insights for further research.

\section{Statement of the problem}

Learning to write in a second language is one of the most challenging aspects of second language learners. They have put lots of time and efforts for acquiring the language and learning to write. In their attempt to master the writing skill, learners inevitably commit errors. One of the major difficulties with writing in English is the use of prepositions, which has been found to be a major source of errors. Since the preposition is an essential component in writing English, it will be valuable to the teachers to be familiar with types of errors. Learners make in order to reduce if not eliminate the problems in the use of appropriate prepositions according to the context. Due to the problems stated above, the present study was designed to investigate the problems encountered by the undergraduate students in the use of preposition within their writing practices. 


\section{Objective of the study}

Based on the researchers' review of the literature and reported findings of the previous studies done in this area, this study aims to shed new light on the following two objectives. The present study made an attempt to identify the difficulties faced by the undergraduate students in using English prepositions while writing. The specific objective made an attempt to analyse in the use of prepositions in particular, of place, time and direction.

\section{Hypothesis}

1. There is no significant difference between gender and prepositional errors.

2. There is no significant difference between the medium of instruction and prepositional errors.

\section{Methodology}

\section{Location}

The location of the study was two Arts and Science Colleges in Coimbatore city which is approximately 7-9 kilometres away from Gandhipuram, Tamil Nadu, India. The colleges were run in two teaching sessions, namely the morning and afternoon session.

\section{Participants}

In this research paper, the researcher considered Arts and Science College students at undergraduate level as subjects of the study. One hundred undergraduate students were selected randomly for the study. Of them, 33 were males and 67 were females. All of them were of 18-21 years of their age. The students were all from the first year majoring in English Literature. The participants had studied the English language around the number of 12 years from the primary to the higher secondary education system.

\section{Research instrument}

To fulfill the purpose of the study, a Cloze test passage was designed and asked to the testees to fill out gaps with the appropriate prepositions that express of place, time and direction. The Cloze test draws the attention of the students to use the correct preposition. However, the experience of gap filling is far more rewarding for learners than any other types of text reading assignment, both emotionally and cognitively. While filling out a blank, testees do not only remember the preposition, but also analyse its use in a sentence. The test was evaluated allocating one score for each correct answer in the Cloze test passage. The researcher used Likert-scale items for the group of respondents scoring (below 6) was assigned 'poor', and those who scoring (7-12) were considered 'below average'. While those scoring from (13-18) were 'average', and those who obtained scores from (19-24) were as 'good' in the given Cloze test passage. The data were tabulated and analysed to compute Chi-Square test, and p-value at 5 per cent level of significance. The data were analysed through SPSS 16.0 software; Chi-Square test was applied to measure the significance of difference between the gender and the medium of instruction on prepositional errors.

\section{Procedure}

For the purpose of assessing students' ability in the use of prepositions of place, time and direction, the test was administered to undergraduate students from two Arts and Science colleges in Coimbatore city. The research with the help of the English teachers of the colleges became approachable to the students first. The students were made to feel at ease. Then the 
test papers were distributed to them and a thorough explanation on how to take the test was provided for them. The subjects were co-operative while administering the test. They were given 30 minutes to fill it out. The test consisted of two parts, namely a personal data sheet was developed to collect the information from the testees related to the variables and tested the performance of the subjects in the use of prepositions of place, time and direction.

\section{Results and discussion}

As stated earlier, the present study analysed the prepositional errors particularly of place, time and direction, committed by the undergraduate students while writing. The study was a quantitative, in-depth enquiry as the interpretation of the data collected from the undergraduate students to find out the reasons and overcome the problems in the use of prepositions. The students found difficulties in the proper use of prepositions of place, time and direction in the given Cloze test. They had problems with choosing the preposition due to the confusion of selecting the correct preposition. The prepositions were familiar to the students but it was difficult for them to place it properly in the sentences.

To determine the differences between gender and the medium of instruction on prepositional errors and in comparison with the students' overall scores on the Cloze test was quantified and compared (Tables 1 \& 3).

Table 1: Findings of the errors in using prepositions by gender

d.f.: Calculated $x^{2}$ Value: 11.221 Table Value: Five percent level: 3.841

Table 1 illustrates that the performance of responses provided on the prepositional errors by scoring procedures. Of the total 100 respondents, $33 \%$ were male and $67 \%$ were

\begin{tabular}{|c|r|r|r|r|}
\hline \multirow{2}{*}{ Gender } & \multicolumn{3}{|c|}{$\begin{array}{l}\text { Complete the Cloze test passage } \\
\text { using suitable prepositions }\end{array}$} & \multirow{2}{*}{ Total } \\
\cline { 2 - 4 } & $\begin{array}{c}\text { Poor } \\
\text { (below 6) }\end{array}$ & $\begin{array}{c}\text { Below } \\
\text { average } \\
(7-12)\end{array}$ & $\begin{array}{r}\text { Average } \\
(13-18)\end{array}$ & \\
\hline Male & 24 & 6 & 3 & 33 \\
\hline Female & 25 & 31 & 11 & 67 \\
\hline Total & 49 & 37 & 14 & 100 \\
\hline
\end{tabular}

female. Among them, 24 (72.72\%) of the male respondents were deemed 'poor' having scored below 6; and 6 (18.18\%) adjudged 'below average' with the scores from 7-12; and there were 3 (9.09\%) students who recorded 'average' having scored 13-18. None of them attained 'good' with scores from 19-24 on the task. Among female testees, 25 (37.31\%) were considered 'poor' having scored 6 or less than $6 ; 31$ (46.27\%) 'below average' and 11 (16.42\%) 'average'. Like the males, none of them scored 'good' with scores from 19-24. However, male and female students committed errors in the use of prepositions of place, time and direction. In addition, the result showed that male students were facing more difficulties in the use of prepositions of place, time and direction as compared to the female learners. The reason for the performance may be the complexity of the rules regarding the usage and the placement of English preposition does contribute to apply the wrong preposition by learners in their target language. The other reason showed their lack of knowledge in the use of preposition and their inability to successfully follow and understand the construction. In addition to this, negligence could be that the students might have not learned intensively in the classroom.

\section{Hypothesis testing}

The role of social variables in the performance of preposition test was identified keeping in view with the help of chi-square value and p-value at 5\% level of significance. To examine if gender and 
medium of instruction are associated with Cloze test on prepositions, the following hypotheses had been framed and tested. The results of the hypotheses were tested below.

\section{Hypothesis 1: There is no significant difference between gender and prepositional errors.}

The results obtained from the students of Cloze test have been analysed with Likert scale, chi-square and $\mathrm{p}$ value calculated. The following table shows it explicitly.

\begin{tabular}{|l|c|c|c|c|}
\hline \multicolumn{1}{|c|}{ Chi square } & $\begin{array}{c}\text { Table } \\
\text { value }\end{array}$ & $\begin{array}{c}\text { Calculated } \\
\text { value }\end{array}$ & $\begin{array}{c}\text { Level of } \\
\text { significance }\end{array}$ & Result \\
\hline $\begin{array}{l}\text { Gender and } \\
\text { prepositional } \\
\text { errors }\end{array}$ & 3.841 & 11.221 & $5 \%$ & Rejected \\
\hline
\end{tabular}

Table 2: Result leading to hypothesis

Table 2 shows that the calculated chi square value 11.221 is greater than the table value of 3.841. Hence, the null hypothesis is rejected with 5 percent significance level. So, the empirical evidence shows that there is a significant association between gender and prepositional errors. Thus, the hypothesis is proved.

\begin{tabular}{|l|c|c|c|c|}
\hline \multirow{2}{*}{$\begin{array}{c}\text { Medium of } \\
\text { Instruction }\end{array}$} & \multicolumn{3}{|c|}{$\begin{array}{c}\text { Complete the Cloze test passage } \\
\text { using suitable preposition }\end{array}$} & \multirow{2}{*}{ Total } \\
\cline { 2 - 4 } & $\begin{array}{c}\text { Poor } \\
\text { (below 6) }\end{array}$ & $\begin{array}{c}\text { Below average } \\
\text { (7-12) }\end{array}$ & $\begin{array}{c}\text { Average } \\
(\mathbf{1 3 - 1 8 )}\end{array}$ & \\
\hline Tamil & 36 & 17 & 3 & 56 \\
\hline English & 13 & 20 & 11 & 44 \\
\hline Total & $\mathbf{4 9}$ & $\mathbf{3 7}$ & $\mathbf{1 7}$ & $\mathbf{1 0 0}$ \\
\hline
\end{tabular}

Table 3: Findings of the errors in using prepositions by medium of instruction

d.f.: Calculated $x^{2}$ value: 14.378 value: Five per cent level: 3.841
Table 3 shows the effect of the medium of instruction upon learners' performance on the use of prepositions. Among the testees whose medium of instruction was Tamil, 36 (64.29\%) scored poorly, 17 (30.36\%) below average and $3(5.35 \%)$ average. The reason for the performance may be attributed to the lack of practice/drill and less attentiveness in L2 learning environment. Among learners with English medium, 13 (29.55\%) faced difficulties and considered themselves poor, whereas $20(45.45 \%)$ performed as below average; 11 (25\%) recorded their performance average in the use of prepositions. In terms of using correct prepositions in the Cloze test, none of the testees scored well. As far as the results are concerned, the percentage of testees who performed poorly in Cloze test on prepositions was high among Tamil medium students while the percentage of respondents who performed better were the English medium students. The reason for the performance is due to exposure to the learning environment. The other reason may be that they have more exposure, which helps them with reading and speaking for the achievement of the language skills.

\section{Hypothesis 2: There is no significant difference between the medium of instruction and prepositional errors.}

To examine if the medium of instruction is associated with Cloze test exercise on prepositions, the above null hypothesis was

\begin{tabular}{|l|c|c|c|c|}
\hline \multicolumn{1}{|c|}{ Chi square } & $\begin{array}{c}\text { Table } \\
\text { value }\end{array}$ & $\begin{array}{c}\text { Calculated } \\
\text { value }\end{array}$ & $\begin{array}{c}\text { Level of } \\
\text { significance }\end{array}$ & Result \\
\hline $\begin{array}{l}\text { Medium of } \\
\text { instruction and } \\
\text { prepositional errors }\end{array}$ & 3.841 & 14.378 & $5 \%$ & Rejected \\
\hline
\end{tabular}

framed and tested. This has been depicted in the following table. 
Table 4: Result leading to hypothesis

Table 4 shows that the calculated chi square value 14.378 is greater than the table value of 3.841. Hence, the null hypothesis is rejected with 5 percent significance level. There is a significant difference between the medium of instruction and prepositional errors. So, the hypothesis is proved.

\section{Overall performance of students' on the use of prepositions of place, time and direction}

The objective of this study was to make an attempt to analyse the use of prepositions in particular, of place, time, and direction. The guided Cloze test exercise contained twenty-four blanks. There were equal questions for prepositions of place, time and

\begin{tabular}{|c|c|c|c|}
\hline $\begin{array}{c}\text { No. of errors } \\
\text { committed }\end{array}$ & $\begin{array}{c}\text { Prepositions } \\
\text { of place }\end{array}$ & $\begin{array}{c}\text { Prepositions } \\
\text { of direction }\end{array}$ & $\begin{array}{c}\text { Prepositions } \\
\text { of time }\end{array}$ \\
\hline 1 & 0 & 1 & 4 \\
\hline 2 & 1 & 0 & 6 \\
\hline 3 & 7 & 6 & 10 \\
\hline 4 & 16 & 15 & 19 \\
\hline 5 & 28 & 27 & 23 \\
\hline 6 & 24 & 20 & 17 \\
\hline 7 & 14 & 21 & 9 \\
\hline 8 & 10 & 10 & 12 \\
\hline
\end{tabular}

direction. The percentage of errors committed by the testees was summarized as follows.

Table 5: Students' performance on the use of prepositions of place, time, and direction in $\%$

Table 5 presents the distribution of errors committed in the use of prepositions of place, time and direction by percentage. Among the three categories, the results show that the highest percentage (i.e. $28 \%$ ) students committed 5 errors in the use of preposition of place. Similarly, 27\% students committed the same number of error in the use of the preposition of direction. Likewise, $23 \%$ students committed the same number of errors in the use of the preposition of time. No person committed one error in the use of the preposition of place, but $1 \%$ students committed errors in the use of the preposition of direction and $4 \%$ students committed errors in the use of preposition of time. In addition, in the Cloze test, 12\% of the respondents committed eight errors in the use of prepositions of time, whereas the equal percent of respondents (i.e. $10 \%$ ) committed the same number of errors in the use of the prepositions of place and direction. Thus, the above table indicates that more errors have been committed by the respondents in the use of prepositions of place and direction rather than prepositions of time. The possible reason for the problems in the use of prepositions of place and direction is due to the lack of understanding the usage and poor prepositional knowledge while writing.

\section{Conclusion}

The present study made an attempt to find out the difficulties in the use of prepositions in particular, of place, time and direction while writing. The research findings revealed that the undergraduate students at the Department of English encountered serious difficulties in using these types of prepositions. The reason for the errors was testees' lack of understanding the usage and the inability to use an appropriate preposition to produce meaningful sentences. The errors committed by the testees were related to syntax and semantics due to the lack of knowledge and practice in L2. The incorrect choice of functional category leads to the distraction of the meaning, which is influenced by L1 in the L2 context. The given hypothesis proved that gender and the medium of 
instruction had significant impact in the wrong use of prepositions while writing in English. The researcher found that the respondents committed more errors in the use of prepositions of place and direction rather than prepositions of time. The present study corroborates with Rumiyati's (2008) findings of preposition, where she says that the students find difficulties in the use of prepositions of direction than the other types. The result also supports the findings of Habash (1982), who claimed that the errors with spatial prepositions were more frequent in number in those with temporal prepositions. However, the result contradicts with the Ahmad's (2011) findings. He claimed that students faced more difficulties in learning prepositions of time and were confused while using prepositions in their writings.

\section{Pedagogical implications}

Based on the results, the researcher suggested that the teacher should pay more attention while teaching prepositions, and give sufficient practice on prepositions of place, time, and direction in the classroom. In order to overcome the problems in the use of prepositions of place, time, and direction, teachers need to give proper guidance to learners to understand the meaning of prepositions and train them to apply the right strategies to become better language users. The teachers should go for participatory language teaching to eliminate such errors immediately in the classroom situation. They need to establish a conducive environment for learning, besides building the learner's confidence and positive self-image through teaching. However, the problem can be overcome if the teacher makes some activities when teaching prepositions. Taking all these issues into account, the English language learners should adopt and practice some pedagogical strategies to overcome their impediments in the process of learning English prepositions. Hence, it is recommended that the students are exposed to this aspect and sufficient practice is given in this area.

\section{About the author}

Dr. J. Saravanan is currently working as Assistant Professor of English at VV College of Engineering, Tisaiyanvilai, Tirunelveli (Dist). Academically he is a Doctorate in Linguistics (Ph.D) from Bharathiar University, Coimbatore, Tamil Nadu - India. Besides, he has possessed M.A in English Literature. He is a highly accomplished professional with abundant research skills and one year teaching experience in Coimbatore. His major areas of research include - Applied Linguistics and English Language Teaching.

\section{References}

Abdulkarim, H. (2008). The communicative approach to teaching English prepositions to Arab students. Unpublished Ph.D. Thesis submitted to Aleppo University, Syria.

Ahmad, N. (2011). Error analysis: Learning articles and prepositions among secondary school students in Pakistan. Interdisciplinary Journal of Contemporary Research in Business VOL2, No.12.

Bennett, D. C. (1972). Some observations concerning the Locative-Directional Distinction, Semiotica 5: 58-88.

Bennett, D.C. (1975). Spatial and temporal uses of English prepositions. London: Longman.

Boers, F., \& Demeceleer, M. (1998). A Cognitive semantic approach to teaching. ELT Journal 52 (3), 197-204. 
Brugman, C. (1981). The story of "over": Polysemy, semantics and the structure of the lexicon. Garland Press.

Brugman, C. (1984). The use of body-part terms as locatives in Chalcatongo Mixtec. Report No. 4 of the Survey of California and other Indian languages, University of California, Berkeley.

Cabuk, S. (2009). The Use of prepositions in second language acquisition process. Unpublished Master's Thesis submitted to the Graduate School of Social Sciences, Department of English Language Teaching, Middle East Technical University.

Chung, E. (2011). Semantic representations for spatial expressions. Unpublished Ph.D. dissertation submitted to University of Illinois at Urbana-Champaign.

Clark, H. (1973). Space, time, semantics and the child. In T. Moore (Ed.). Cognitive development and the acquisition of language (pp. 28-63). New York: Academic Press.

Cooper, G. S. (1968). A Semantic analysis of English locative prepositions. Airforce. Redford, Massachutes: Cambridge Research Laboratories.

Endley, M. (2010). Linguistic perspectives on English grammar: A Guide for EFL teachers. ISBN 978-1-61735-168-6.

Habbash, S. (1982). Common errors in the use of English prepositions in the written work of UNRWA students at the end of the Preparatory Cycle in the Jerusalem Area. Unpublished M.A. Thesis submitted to Birzeit University.

Hawkins, B.W. (1984). The semantics of English spatial prepositions. Unpublished Ph.D. dissertation submitted to the University of California, San Diego.

Herskovits, A. (1986). Language and spatial cognition: An interdisciplinary study of the prepositions in English. Cambridge, England: Cambridge University Press.

Hill, J. (1989). Grammar and practice: Self-study with key. Language Teaching Publications. P.224.

Horberg, T. (2006). Influences on form and function on spatial relations: establishing functional and geometric influences on productive prepositions in Swedish. Unpublished Thesis in General Linguistics submitted to Stockholm University.

Huddleston, R. (1984). Introduction to the grammar of English. Cambridge: Cambridge University Press.

Jackendoff, R. (1983). Semantics and cognition. Cambridge, MA: MIT Press.

Jackendoff, R. (1990). Semantics structures. Cambridge, MA: MIT Press.

Kemmerer, D. (2005). The spatial and temporal meaning of English prepositions can be independently impaired. Neuropsychologia, 43, 797806.

Kenndy, G. (2003). Structure and meaning in English: A guide for teachers. London: Pearson Education Limited, p. 257.

Kim, L. C. (2001). An error analysis of English prepositions in the written work of upper secondary Malay students. Unpublished Master's Thesis submitted to the Faculty of Language and Linguistics, University of Malaya.

Kracht, M. (2002). On the semantics of locatives. Linguistics and Philosophy 25: 157-232. 
Lakoff, G. (1987). Women, fire, and other dangerous things. Chicago: University of Chicago Press.

Landau, B., and R. Jackendoff. (1993). "What" and "where" in spatial language and spatial cognition. Behavioural and Brain Sciences, 15: 217-265.

Leech, G. N. (1969). Towards a semantic description of English. London: Longman.

Lindstromberg, S. (1998). English prepositions explained. Amsterdam: John Benjamin Publishing Company.

Lindstromberg, S. (2000). English prepositions explained. Amsterdam: John Benjamin Publishing Company.

Miller, G. \& Johnson-Laird. (1976). Language and perception. Cambridge: Harvard University Press.

Nam, S. (1995). The Semantics of locative prepositional phrases in English. Unpublished Ph.D. dissertation submitted to University of California, Los Angels.

Quirk et al. (1972). A grammar of contemporary English. London: Longman.p.377.

Quirk et al. (1985). A comprehensive grammar of the English language.London: Longman Group Limited. pp. 657.

Rumiyati, W. (2008). Errors in using English prepositions made by the second year students of SMU Muhammadiyah 1 Gresik. Unpublished undergraduate Thesis submitted to JIPPTUMG, Universitas Muhammadiyah Gresik. Retrieved: 23.02.2008: http:// digilib.umg. ac.id/gdl.php
$?$ mod=browse\&op =read $\& \mathrm{id}=$ jipptumg-rumiyati-34.

Simon R. M. (2000). The Use of place prepositions among some selected senior secondary school students in Kaduna Metropolis. Unpublished Master's Thesis submitted to the Postgraduate School, Ahmadu Bello University, Abu, Zaria.

Swan, M. (2005). Practical English usage. Oxford:Oxford University Press.

Talmy, L. (1983). How language structures space. In H. and L. Acredolo (Eds.), Spatial orientation: theory, research, and application. New York: Plenum Press.

Tseng, J. L. (2000). The representation and selection of prepositions. Unpublished Ph.D. Thesis submitted to University of Edinburg.

Tyler, A., \& V. Evans (2003). The semantics of English prepositions: spatial scenes, embodied meaning and cognition. Cambridge: Cambridge University Press.

Vandeloise, C. (1991). Spatial prepositions: a case study from French. Chicago: University of Chicago Press.

Zwarts, J. (1997). Vectors as relative positions: A compositional semantics of modified PPs. Journal of Semantics, 14: 57-86.

Zwarts, J., \& Winter, Y. (2000). Vector space semantics: A modeltheoretic analysis of locative prepositions. Journal of Login, Language, and Information, (9), 169-211.

Zwarts, J. (2005). Prepositional aspect and the algebra of paths. Linguistics and Philosophy 28.6: 739-779. 